\title{
Caracterização morfológica de frutos, sementes, plântulas e germinação de sementes de Casearia decandra
}

\author{
Sérgio Haliski ${ }^{1}$, Nelson Luiz Cosmoํㅜㄹ Alessandra Mara Gogosz ${ }^{1}$, Suelen Santos Rego ${ }^{1}$, Antonio Carlos Nogueira ${ }^{1}$, \\ Yoshiko Saito Kuniyoshi ${ }^{1}$
}

${ }^{1}$ Universidade Federal do Paraná, Departamento de Ciências Florestais, Av. Pref. Lothário Meissner, 900, Jardim Botânico, CEP 80210-170, Curitiba, PR, Brasil

\author{
"Autor correspondente: \\ haliski25@hotmail.com \\ Termos para indexação: \\ Salicaceae \\ Temperatura \\ Substrato \\ Florestal
}

Index terms:

Salicaceae

Temperature

Substrate

Forest

Histórico do artigo:

Recebido em 31/10/2012

Aprovado em 01/07/2013

Publicado em 30/09/2013

doi: 10.4336/2013.pfb.33.75.451
Resumo - Este trabalho tem como objetivos caracterizar morfologicamente os frutos, sementes e o desenvolvimento de plântulas de Casearia decandra, e verificar as melhores temperaturas e substratos para a germinação das sementes. Os frutos foram coletados de 13 matrizes no município de Irati, PR. Foram realizados testes para obter o peso de mil sementes, o número de sementes por quilo e o grau de umidade das sementes. Para testar a influência de diferentes temperaturas e substratos na germinação utilizaram-se quatro temperaturas: $20^{\circ} \mathrm{C}, 25{ }^{\circ} \mathrm{C}, 30^{\circ} \mathrm{C}$ e $35^{\circ} \mathrm{C}$ e quatro substratos: areia, papel toalha, rolo papel e vermiculita. $\mathrm{O}$ fruto é esférico, com pericarpo seco, pouco espesso, com superfície glabra, lisa e amarelo-clara. A semente tem forma elipsóide, tegumento cartáceo, creme e levemente estriado. Possui arilo carnoso e alaranjado, e endosperma carnoso. O embrião é espatulado, verde-claro, com eixo curto e paracotilédones cordiformes. A plântula é do tipo epígea e fanerocotiledonar. Os paracotilédones são opostos, cordiformes, e com margem inteira. Os eofilos são alternos, elípticos e com margem serreada. No epicótilo ocorrem pequenas estípulas axiais. Os melhores resultados de germinação foram obtidos com as temperaturas $20^{\circ} \mathrm{C}, 25^{\circ} \mathrm{C}$ e $30^{\circ} \mathrm{C}$ com o substrato rolo de papel.

\section{Morphological characterization and germination of seeds of Casearia decandra}

\begin{abstract}
This study aimed at to characterize morphologically the fruits, seeds and seedling development of Casearia decandra and examine the best substrate and temperature for seed germination. The fruits were collected from 13 mothers in the municipality of Irati, Parana State, Brazil. Tests were conducted to determine the weight of 1,000 seeds, number of seeds per kilogram and the seeds moisture content. To test the influence of different substrate and temperature on germination it was tested four temperatures: $20^{\circ} \mathrm{C}, 25^{\circ} \mathrm{C}, 30^{\circ} \mathrm{C}$ and $35^{\circ} \mathrm{C}$ on four substrates: sand, paper towels, roll paper and vermiculite. The fruit is spherical, with dry pericarp, thin, with glabrous , smooth, and light yellow surface. The seed presents ellipsoid shape, chartaceous, creamy and lightly striated tegument. It has fleshy and orange arils, and fleshy endosperm. The embryo is spatulate, light green, with short axis and heart-shaped paracotyledons. The seedling is epigeous and phanerocotyledonal. The paracotyledons are opposite, heart-shaped and with entire margin. Eophylls are alternate, elliptical, with serrate margins. In the epicotyl occurs small axial stipules. The best germination results were obtained with temperatures of $20^{\circ} \mathrm{C}, 25^{\circ} \mathrm{C}$ and $30^{\circ} \mathrm{C}$ with the substrate paper roll.
\end{abstract}




\section{Introdução}

O gênero Casearia tem sido subordinado a diferentes famílias, desde o século XIX aos nossos dias (Marquete \& Vaz, 2007). Anteriormente enquadrada em Flacourtiaceae, Casearia decandra foi recentemente subordinada à Família Salicaceae, segundo o sistema de classificação APG II.

Essa espécie tem uma ampla distribuição, desde Honduras até o Panamá, Antilhas, Bolívia, Paraguai, Brasil, Uruguai e norte da Argentina. No Brasil, ocorre na Floresta Ombrófila Mista, na Floresta Ombrófila Densa, bem como em áreas de transição para Savana (Klein \& Sleumer, 1984; Longhi, 1995; Marquete \& Vaz, 2007), principalmente no interior dos sub-bosques, em solos úmidos. Na Floresta Ombrófila Mista, ocorre em associação com Ocotea porosa, Ilex paraguariensis e Allophylus guaraniticus, especialmente no estrato médio da floresta. (Klein \& Sleumer, 1984).

Essa espécie pode ser utilizada para recuperação de áreas degradadas, pois seus frutos são comestíveis e muito procurados por aves, responsáveis por sua dispersão (Klein \& Sleumer, 1984). Segundo Carvalho (1994), a sua madeira é utilizada na confecção de utensílios leves, brinquedos e também para lenha e carvão, sendo considerada moderadamente pesada $\left(0,7 \mathrm{~g} \mathrm{~cm}^{-3}\right)$. Durante a primavera, ainda quando está sem folhas, a espécie produz uma grande quantidade de flores brancas, que exalam um aroma forte e particular que atrai abelhas, fornecendo uma grande quantidade de mel de excelente qualidade.

A descrição e ilustração de caracteres morfológicos de sementes e plântulas são úteis para o conhecimento do desenvolvimento das espécies florestais nativas, pois a partir de reconhecimentos das estruturas da semente é possível obter indicações sobre germinação, armazenamento, viabilidade e métodos de semeadura (Kuniyoshi, 1983).

Apesar disso, assim como ocorre com diversas espécies da flora brasileira, são escassas as informações disponíveis sobre Casearia decandra, tanto em relação a aspectos morfológicos e ecológicos, quanto à sua silvicultura. $\mathrm{O}$ estudo da morfologia de frutos e sementes das espécies florestais, bem como o entendimento do processo germinativo e do desenvolvimento das plântulas contribuem para viabilizar tanto sua conservação, quanto sua utilização.

O teste de germinação é o método mais utilizado para se determinar a qualidade de sementes de um determinado lote e possibilita a avaliação da viabilidade sob condições favoráveis (Oliveira et al, 2008). Segundo Malavasi (1988), existem fatores que podem determinar diferentes respostas na germinação como, por exemplo, a temperatura que pode ocorrer como mínima, ótima e máxima, porém, para a maioria das sementes florestais, a temperatura ótima permanece entre 15 e $30^{\circ} \mathrm{C}$. Outro fator importante para a germinação é o substrato em que a semente é colocada para germinar, que tem a função de manter a umidade, preservando as condições ideais para que esta ocorra (Piña-Rodrigues \& Vieira, 1988). $\mathrm{Na}$ escolha do substrato deve ser levado em consideração o tamanho da semente, sua exigência com relação à quantidade de água, sua sensibilidade ao fator luz e a facilidade que o mesmo oferece para a realização das contagens e para a avaliação das plântulas (Figliolia et al., 1993).

Desta forma, este trabalho teve como objetivos caracterizar morfologicamente os frutos, as sementes e o desenvolvimento das plântulas de Casearia decandra, bem como determinar as melhores temperaturas e os substratos adequados para a germinação das sementes.

\section{Material e métodos}

Os frutos foram coletados de treze matrizes, nos meses de dezembro de 2008 e janeiro de 2009, no município de Irati, PR, despolpados através da maceração e lavagem em água corrente, e as sementes deixadas secar a sombra.

\section{Caracterização morfológica do fruto, da semente e da plântula}

Foram utilizadas 50 unidades aleatoriamente para descrever e ilustrar morfologicamente os frutos e as sementes. As observações foram feitas com microscópio estereoscópico e a olho nu. Com auxílio de um paquímetro digital, foram medidos o diâmetro dos frutos e o comprimento, largura e espessura das sementes e expressos em mm. As características morfológicas relevantes do fruto e da semente foram ilustradas e descritas, tendo sido consultados como base para a classificação os trabalhos de Kuniyoshi (1983), Spjut (1994) e Barroso et al. (1999).

Para o acompanhamento do desenvolvimento das fases iniciais da plântula (emissão da radícula) foram colocadas para germinar 100 sementes em gerbox desinfetados com álcool $70 \%$, contendo quatro folhas de papel toalha esterilizado e umedecido com água 
destilada. Os gerbox foram colocados em germinador regulado a $25{ }^{\circ} \mathrm{C}$. Para o acompanhamento das fases finais da plântula (emissão dos eofilos) foram colocadas 100 sementes em bandejas de plástico contendo vermiculita e realizadas ilustrações das fases, desde a emissão da radícula até o desenvolvimento dos eófilos. O material botânico utilizado foi conservado em álcool $70 \%$. A terminologia utilizada foi baseada nos trabalhos de Vogel (1980) e Kuniyoshi (1983).

\section{Análises físicas das sementes}

Foram realizados testes para obter o peso de mil sementes, o número de sementes por quilo e o grau de umidade das sementes, conforme as regras para análise de sementes (Brasil, 2009). Para o peso de mil sementes foram utilizadas oito amostras de 100 sementes, e para o teor de umidade, três repetições de 200 sementes (aproximadamente $4 \mathrm{~g}$ de sementes).

\section{Influência de diferentes temperaturas e substratos na germinação}

$\mathrm{O}$ experimento baseou-se em quatro temperaturas: $20{ }^{\circ} \mathrm{C}, 25{ }^{\circ} \mathrm{C}, 30{ }^{\circ} \mathrm{C}$ e $35^{\circ} \mathrm{C}$; e quatro formas de semeadura nos substratos: areia, papel toalha, rolo papel e vermiculita, com cinco repetições de 40 sementes em cada tratamento. Os substratos foram previamente esterilizados em estufa regulada a temperatura de $105^{\circ} \mathrm{C}$ por $24 \mathrm{~h}$. Para o substrato areia, foram colocados em gerbox $120 \mathrm{~g}$ e adicionados $29 \mathrm{~mL}$ de água destilada, e para o substrato papel toalha foram utilizadas quatro folhas umedecidas com $12 \mathrm{~mL}$ de água destilada. $\mathrm{O}$ substrato rolo de papel foi constituído de quatro folhas de papel toalha umedecidos com água destilada, sendo que as sementes permaneceram entre as folhas enroladas e deixadas na posição horizontal no germinador. Para o substrato vermiculita, utilizou-se a de granulometria média e colocados $20 \mathrm{~g}$ em gerbox e adicionados $70 \mathrm{~mL}$ de água. Os testes foram realizados em germinadores modelo Biomatic regulados às temperaturas de $20^{\circ} \mathrm{C}$, $25^{\circ} \mathrm{C}, 30^{\circ} \mathrm{C}$ e $35^{\circ} \mathrm{C}$.

Durante o período de realização dos experimentos verificou-se que a água dos substratos evaporou e com isso foi necessário realizar uma nova adição de água. Este umedecimento foi realizado sem que atingisse a capacidade de campo dos substratos.

Foram avaliados a porcentagem, o tempo médio (TM) (Laboriau, 1983) e o índice de velocidade de germinação (IVG) (Maguire, 1962), e as avaliações realizadas duas vezes ao dia: às 8 e $18 \mathrm{~h}$, sendo que o critério de germinação adotado foi o critério botânico: emissão da radícula superior a $2 \mathrm{~mm}$ de comprimento.

$\mathrm{O}$ teste de germinação foi analisado segundo o delineamento inteiramente casualizado. A influência da temperatura e do substrato foi analisado em esquema fatorial 4 x 4 (4 temperaturas $\mathrm{x} 4$ substratos), com cinco repetições para cada tratamento. Os dados obtidos para a porcentagem, tempo médio e índice de velocidade de germinação foram submetidos ao teste de Bartlett e à análise de variância. Para os dados de porcentagem de germinação as médias foram comparadas pelo teste de Tukey a $5 \%$ de probabilidade, e para os dados de IVG e TM os dados foram submetidos ao teste de comparação múltipla não paramétrica a 5\% de probabilidade.

\section{Resultados e discussão}

\section{Caracterização morfológica de frutos, sementes e plântulas}

Casearia. decandra tem fruto esférico, com pericarpo seco, pouco espesso, com superfície glabra, lisa e amarelaclara (Figura 1A). O fruto mede de 6,8 a 11,2 cm (11,15\% cv). Barroso (1999) enquadra o fruto de Casearia decandra no tipo cápsula loculicida, e subdivide os frutos de Flacourtiaceae em deiscentes, aparentemente indeiscentes, tardiamente deiscentes e perfeitamente indeiscentes, e classifica os de Casearia em tardiamente deiscentes.

A semente tem forma elipsóide, tegumento cartáceo, creme, levemente estriado e possui em média $4,0 \mathrm{~mm}$ de comprimento, 3,2 $\mathrm{mm}$ de largura e 2,2 $\mathrm{mm}$ de espessura (Tabela 1). Ao redor destas ocorre arilo carnoso, alaranjado, que preenche completamente o fruto, podendo ser confundido com mesocarpo. A semente possui endosperma carnoso e o embrião é axial, foliáceo, espatulado, dominante à total, verde-claro, com eixo curto e paracotilédones cordiformes (Figura 1B e C).

A germinação inicia-se no $3^{\circ}$ dia, se estendendo até o $23^{\circ}$ dia com a protrusão e expansão da raiz primária e subsequente elevação do hipocótilo. A germinação de Casearia decandra é considerada rápida segundo $\mathrm{Ng}$ (1978). De acordo com este autor, uma germinação rápida de todas as sementes viáveis em um curto período de tempo é uma estratégia bem sucedida, mas ineficaz, pois as plântulas irão competir entre elas. Estas espécies estarão mais vulneráveis à extinção, pois são mais suscetíveis ao ataque de predadores e não possuem um banco de sementes.

Pesq. flor. bras., Colombo, v. 33, n. 75, p. 253-259, jul./set. 2013 


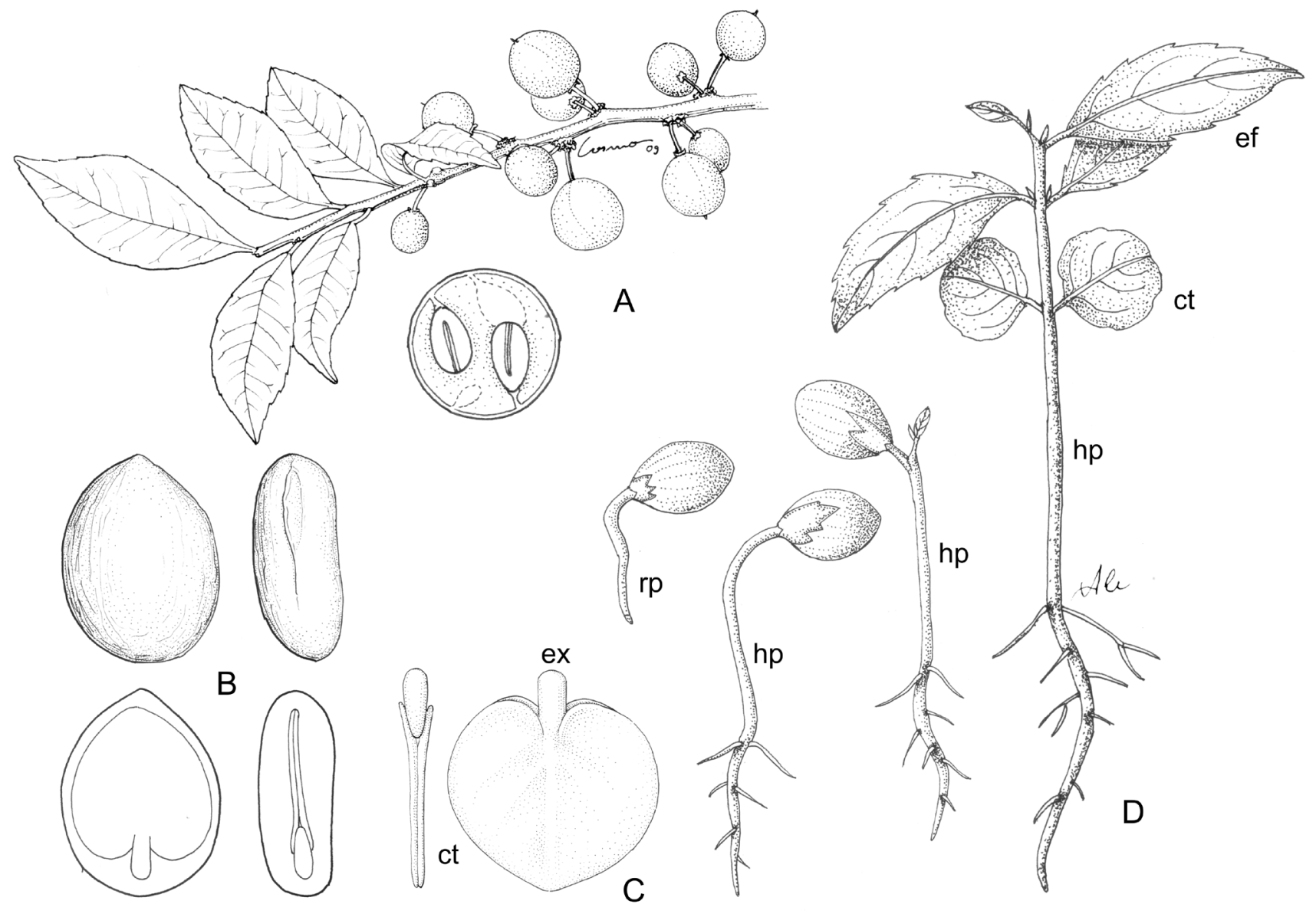

Figura 1. Morfologia do fruto, semente e plântula de Casearia decandra. A- Ramo com frutos e corte transversal do fruto; B - aspecto externo e interno da semente; C - embrião; D - fases de desenvolvimento da plântula; ct - cotilédone; ef - eófilo; ex - eixo hipocótilo-radicular; hp - hipocótilo; rp - raiz primária. (Ilustrações: Cosmo, N.L.; Gogosz, A.M.).

Tabela 1. Comprimento, largura e espessura das sementes de Casearia decandra.

\begin{tabular}{lccccc}
\hline Dimensões $(\mathbf{m m})$ & Mínimo & Média & Máximo & Desvio padrão & Coeficiente de variação (\%) \\
\hline Comprimento & 3,0 & 4,02 & 5,0 & 0,43 & 10,65 \\
Largura & 3,0 & 3,28 & 4,0 & 0,45 & 13,83 \\
Espessura & 2,0 & 2,22 & 3,0 & 0,42 & 18,85 \\
\hline
\end{tabular}

Inicialmente os paracotilédones permanecem envoltos pelo tegumento, provavelmente exercendo função haustorial, até que as reservas do endosperma sejam consumidas. Em torno de vinte dias após o início do desenvolvimento da plântula ocorre a abertura dos paracotilédones e logo em seguida inicia-se o desenvolvimento dos eófilos (Figura 1D).

A plântula de Casearia decandra se enquadra, portanto, no tipo epígea e fanerocotiledonar. Os paracotilédones são opostos, cordiformes, com base truncada e ápice arredondado a retuso, com margem inteira. Os eófilos são alternos, elípticos, com base atenuada, ápice agudo e margem serreada. Tanto paracotilédones quanto eófilos são verde-claros, membranáceos, glabros e têm venação peninérvea. O hipocótilo é cilíndrico, tem superfície pubescente, com região do colo pouco distinta, apenas com leve espessamento. No epicótilo ocorrem pequenas estípulas axiais (Figura 1D). 
A plântula de Casearia decandra é classificada como PEF (fanerocotiledonar, epígea, foliácea) de acordo com Garwood (1996), que classificou as plântulas em cinco tipos: fanerocotiledonar, epígea, cotilédone foliáceo (PEF); fanerocotiledonar, epígea, cotilédone de reserva (PER); fanerocotiledonar, hipógea, cotiléone de reserva (PHR); criptocotiledonar, hipógea, cotilédone de reserva (CHR) e criptocotiledonar, epígea, cotiléone de reserva (CER).

\section{Análises físicas das sementes}

Mil sementes pesam em média 28,05 g e em um quilograma contêm 35.650 sementes. Para o grau de umidade obteve-se $54 \%$.

\section{Influência de diferentes temperaturas e substratos na germinação}

Para a porcentagem de germinação não houve interação entre as temperaturas e os substratos. Entre os substratos não houve diferença significativa para a porcentagem de germinação, porém entre as temperaturas verificouse que na de $35{ }^{\circ} \mathrm{C}$ a porcentagem de germinação foi estatisticamente menor que na de $20{ }^{\circ} \mathrm{C}$ e $30^{\circ} \mathrm{C}$ (Tabela 2). As temperaturas próximas à superfície do solo podem variar bastante entre diferentes ambientes. Grandes clareiras nas florestas tropicais, por exemplo, podem apresentar maiores amplitudes térmicas do que locais sombreados do sub-bosque (Melo et al., 2004). Desta forma, como Casearia decandra geralmente se estabelece no interior da floresta, é esperado que suas sementes apresentem baixa porcentagem de germinação em temperaturas elevadas $\left(35^{\circ} \mathrm{C}\right)$.

A temperatura ideal para a germinação de Casearia decandra encontrada neste trabalho está na faixa de 20 a $30{ }^{\circ} \mathrm{C}$, que, de acordo com Borges \& Rena (1993), mostra-se adequada para a germinação de um grande número de espécies subtropicais e tropicais.

Já para o índice de velocidade de germinação, verificouse interação entre os fatores. A temperatura de $30{ }^{\circ} \mathrm{C}$ obteve o maior índice em todos os substratos testados e o substrato rolo de papel obteve os maiores valores nas temperaturas $20^{\circ} \mathrm{C}, 25^{\circ} \mathrm{Ce} 30^{\circ} \mathrm{C}$, exceto na temperatura de $35{ }^{\circ} \mathrm{C}$, na qual os substratos areia e vermiculita obtiveram os maiores valores (Tabela 3). Para Tabebuia serratifolia, Tabebuia chrysotricha e Tabebuia roseo-alba a velocidade de germinação foi maior nas temperaturas de 25 e $30^{\circ} \mathrm{C}$ (Santos et al., 2005). As sementes de Casearia sylvestris apresentaram redução significativa dos valores de velocidade quando submetidas à temperatura de $33^{\circ} \mathrm{C}$ (Imatomi et al., 2009).

Para o tempo médio (Tabela 4) houve interação entre as temperaturas e os substratos. Do mesmo modo que no índice de velocidade de germinação, no parâmetro tempo médio o substrato rolo de papel obteve os melhores valores nas temperaturas $20{ }^{\circ} \mathrm{C}, 25^{\circ} \mathrm{C}$ e $30^{\circ} \mathrm{C}$. Na temperatura de $35^{\circ} \mathrm{C}$ foi o substrato vermiculita que obteve o menor valor. Nos substratos testados a temperatura $30^{\circ} \mathrm{C}$ obteve os menores valores (Tabela 4).

Tabela 2. Porcentagem de germinação das sementes de Casearia decandra em diferentes substratos e temperaturas.

\begin{tabular}{lccccc}
\hline & \multicolumn{5}{c}{ Temperaturas ${ }^{\mathbf{0}} \mathbf{C}$} \\
\cline { 2 - 6 } Substratos & 20 & 25 & 30 & 35 & Médias \\
\hline Papel toalha & 96,0 & 96,0 & 93,0 & 88,0 & $93,2 \mathrm{~A}$ \\
Rolo de papel & 94,5 & 92,0 & 96,5 & 90,0 & $93,2 \mathrm{~A}$ \\
Areia & 96,0 & 94,0 & 96,5 & 94,5 & $93,2 \mathrm{~A}$ \\
Vermiculita & 98,0 & 95,5 & 98,5 & 95,5 & $96,9 \mathrm{~A}$ \\
\hline Médias & $96,1 \mathrm{~A}$ & $94,4 \mathrm{AB}$ & $96,1 \mathrm{~A}$ & $92,0 \mathrm{~B}$ & \\
\hline
\end{tabular}

Médias seguidas por letras distintas diferem entre si pelo teste de Tukey a $5 \%$ de probabilidade.

Tabela 3. Índice de velocidade de germinação das sementes de Casearia decandra em diferentes substratos e temperaturas.

\begin{tabular}{lcccc}
\hline & \multicolumn{3}{c}{ Temperaturas $^{\circ} \mathbf{C}$} \\
\cline { 2 - 5 } Substratos & 20 & 25 & 30 & 35 \\
\hline Papel toalha & $4,62 \mathrm{Cd}$ & $5,98 \mathrm{Dc}$ & $6,35 \mathrm{Da}$ & $5,76 \mathrm{Cb}$ \\
Rolo de papel & $5,85 \mathrm{Ad}$ & $7,15 \mathrm{Ab}$ & $9,30 \mathrm{Aa}$ & $6,47 \mathrm{Bc}$ \\
Areia & $5,11 \mathrm{Bd}$ & $6,23 \mathrm{Cc}$ & $6,98 \mathrm{Ca}$ & $6,65 \mathrm{Ab}$ \\
Vermiculita & $5,26 \mathrm{Bd}$ & $6,40 \mathrm{Bc}$ & $7,61 \mathrm{Ba}$ & $6,76 \mathrm{Ab}$ \\
\hline
\end{tabular}

Médias seguidas por letras distintas maiúsculas nas colunas e minúsculas nas linhas diferem entre si pelo teste de comparação múltipla não paramétrica a $5 \%$ de probabilidade. 
De acordo com Taiz \& Zeiger (2004), temperaturas elevadas provocam diminuição do suprimento de aminoácidos livres, da síntese protéica e das reações anabólicas, podendo desnaturar proteínas e alterar a permeabilidade das membranas. Ao contrário, temperaturas mais baixas, provocam atraso na germinação e no crescimento, devido à redução da atividade das enzimas envolvidas na respiração e no metabolismo (Marcos Filho, 2005). Isto explica o fato das sementes submetidas à temperatura de $20^{\circ} \mathrm{C}$ e $25^{\circ} \mathrm{C}$ levarem mais tempo para germinar que as de $30^{\circ} \mathrm{C}$.

Tabela 4. Tempo médio de germinação das sementes de Casearia decandra em diferentes substratos e temperaturas.

\begin{tabular}{lcccc}
\hline & \multicolumn{4}{c}{ Temperaturas ${ }^{\circ} \mathbf{C}$} \\
\cline { 2 - 5 } Substratos & 20 & 25 & 30 & 35 \\
\hline Papel toalha & $8,61 \mathrm{Aa}$ & $6,63 \mathrm{Ab}$ & $6,26 \mathrm{Ac}$ & $6,52 \mathrm{Ab}$ \\
Rolo de papel & $7,02 \mathrm{Ca}$ & $5,70 \mathrm{Cc}$ & $4,56 \mathrm{Dd}$ & $6,34 \mathrm{Bb}$ \\
Areia & $7,92 \mathrm{Ba}$ & $6,38 \mathrm{Bb}$ & $5,93 \mathrm{Bd}$ & $6,18 \mathrm{Bc}$ \\
Vermiculita & $7,80 \mathrm{Ba}$ & $6,30 \mathrm{Ab}$ & $5,40 \mathrm{Cd}$ & $5,83 \mathrm{Cc}$ \\
\hline
\end{tabular}

Médias seguidas por letras distintas maiúsculas nas colunas e minúsculas nas linhas diferem entre si pelo teste de comparação múltipla não paramétrica a $5 \%$ de probabilidade.

Desta forma, para os testes de germinação com as sementes de Casearia decandra recomenda-se a utilização das temperaturas $20^{\circ} \mathrm{C}, 25^{\circ} \mathrm{C}$ e $30^{\circ} \mathrm{C}$ com o substrato rolo de papel. Para Casearia sylvestris, Imatomi et al. (2009) e Rosa \& Ferreira (2001) encontraram resultados semelhantes com relação a faixa ótima de temperatura para a germinação que foi de $20^{\circ} \mathrm{C}$ a $30{ }^{\circ} \mathrm{C}$.

Para a germinação de algumas espécies florestais, foi observado que o substrato papel toalha apresentou baixa resistência quando disposto em rolos de papel (Willan, 1991; Figliolia \& Pina Rodrigues, 1995). No entanto, neste trabalho, tal fato não foi observado, pois a germinação desta espécie é rápida (4 a 8 dias) e com isso o substrato rolo de papel se manteve em boas condições.

Um fator importante a ser considerado é a interação temperatura e substrato, pois a capacidade de retenção de água do substrato pode ser responsável por diferentes respostas obtidas até para a mesma temperatura (Figliolia et al., 1993), como verificado neste trabalho para o substrato rolo de papel, que apresentou maior índice de velocidade de germinação e menor tempo médio nas temperaturas $20^{\circ} \mathrm{C}, 25^{\circ} \mathrm{C}$ e $30^{\circ} \mathrm{C}$, sendo que o mesmo não ocorreu na temperatura $35^{\circ} \mathrm{C}$.

\section{Conclusões}

O fruto de Casearia decandra é uma cápsula loculicida, esférica, com pericarpo seco, de coloração amarela-clara.

A semente é albuminosa, elipsóide, com tegumento cartáceo, creme e levemente estriado. Possui arilo carnoso e alaranjado, sendo o embrião espatulado, verdeclaro, com eixo curto e paracotilédones cordiformes.

A plântula é epígea, fanerocotiledonar.

Para os testes de germinação com as sementes de Casearia decandra recomenda-se a utilização das temperaturas $20^{\circ} \mathrm{C}, 25^{\circ} \mathrm{C}$ e $30^{\circ} \mathrm{C}$ com o substrato rolo de papel.

\section{Referências}

BARROSO, G. M.; MORIM, M. P.; PEIXOTO, A. L.; ICHASO, C. L. F. Frutos e sementes: morfologia aplicada à sistemática de dicotiledôneas. Viçosa, MG: Ed UFV, 1999. 443 p.

BORGES, E. E. de L.; RENA, A.B. Germinação de sementes. In: AGUIAR, I. B. de; PIÑA-RODRIGUES, F. C. M.; FIGLIOLIA, M. B. Sementes florestais tropicais. Brasília, DF: ABRATES, 1993. p. $83-135$.

BRASIL. Ministério da Agricultura e Reforma Agrária. Regras para análises de sementes. Brasília, DF, 2009. 399 p.

CARVALHO, P. E. R. Espécies florestais brasileiras: recomendações silviculturais, potencialidades e uso da madeira. Colombo: Embrapa Florestas, 1994. 101 p.

FIGLIOLIA, M. B.; OLIVEIRA, E. de C.; PINÃ-RODRIGUES, F. C. M. Análise de sementes. In: AGUIAR, I. B. de; PIÑA-RODRIGUES, F. C. M.; FIGLIOLIA, M. B. Sementes florestais tropicais. Brasília, DF: ABRATES, 1993. p. 137-174.

FIGLIOLIA, M. B.; PIÑA-RODRIGUES, F. C. M. Considerações práticas sobre o teste de germinação. IF Série Registros, São Paulo, n. 14, p. 45-59, abr. 1995. Manual técnico de sementes florestais.

GARWOOD, N. C. Functional morphology of tropical tree seedling. In: SWAINE, M. D. (Ed.). The ecology of tropical forest tree seedling. Paris: Unesco and Parthenom Publishing Grouo, 1996. p. 59-129. 
IMATOMI, M.; PEREZ, S. C. J. G. de A.; FERREIRA, A. G. Caracterização e comportamento germinativo de sementes de Casearia sylvestris swartz (Salicaceae). Revista Brasileira de Sementes, Brasília, DF, v. 31, n. 2, p. 36-47, 2009.

KLEIN, R. M.; SLEUMER, H. O. Flacourtiaceae. In: REITZ, P. R. Flora Ilustrada Catarinense, Itajaí: Herbário Barbosa Rodrigues, 1984. p. 1-95

KUNIYOSHI, Y. S. Morfologia da semente e da germinação de 25 espécies arbóreas de uma Floresta com Araucária. 1983. 233 f. Dissertação (Mestrado em Ciências Florestais) - Universidade Federal do Paraná, Curitiba.

LABORIAU, L. G. A germinação das sementes. Washington, DC: Secretaria Geral da Organização dos Estados Americanos, 1983. $174 \mathrm{p}$.

LONGHI, R. A. Livro das árvores e arvoretas do sul. 2. ed. Porto Alegre: L \& PM, 1995. 176 p.

MAGUIRE, J. D. Speed of germination aid in selection and evaluation for seedling emergence and vigor. Crop Science, Madison, v. 2, n. 1, p. 176-177, 1962.

MALAVASI, M. M. Germinação de sementes. In: PIÑA-RODRIGUES, F. C. M. Manual de análise de sementes florestais. Campinas: Fundação Cargill, 1988. p. 25-40.

MARCOS FILHO, J. Fisiologia de sementes de plantas cultivadas. Piracicaba: FEALQ, 2005. 495p.

MARQUETE, R.; VAZ, A. M. S. da F. O gênero Casearia no estado do Rio de Janeiro, Brasil. Rodriguésia, Rio de Janeiro, v. 58, n. 4, p. 705-738, 2007.

MELO, M. da G. G. de; MENDONÇA, M. S. de; MENDES, A. M. da S. Análise morfológica de sementes, germinação e plântulas de jatobá (Hymenaea intermedia Ducke var. adenotricha (Ducke) Lee \& Lang.) (Leguminosae- Caesalpinioideae). Acta Amazonica, Manaus, v. 34, n. 1, p. 9-14, 2004.

NG, F. S. P. Strategies of establishment in Malayan forest trees. In: TOMLINSON, P. B. P.; ZIMMERMANN, M. H. Tropical trees as living systems. London: Cambridge University Press, 1978. p. $129-162$.
OLIVEIRA, E. de C. Morfologia de plântulas. In: AGUIAR, I. B. de; PIÑARODRIGUES, F. C. M.; FIGLIOLIA, M. B. Sementes florestais tropicais. Brasília, DF: ABRATES, 1993. p. 175-213.

OLIVEIRA, L. M.; DAVIDE, A. C.; CARVALHO, M. L. M. Teste de germinação de sementes de Peltophorum dubium (SPREGEL) TAUBERT - Fabaceae. Revista Floresta, Curitiba, v. 38, n. 3, p. 545-551, 2008.

PIÑA-RODRIGUES, F. C. M.; VIEIRA, J. D. Teste de germinação. In: PIÑA RODRIGUES, F. C. M. Manual de análise de sementes florestais. Campinas: Fundação Cargill, 1988. p. 70-90.

ROSA, S. G. T. da; FERREIRA, A. G. Germinação de sementes de plantas medicinais lenhosas. Acta Botânica Brasílica, Brasília, DF, v. 15, n. 2, p. 147-154, 2001.

SANTOS, D. L. dos; SUGAHARA, V. Y.; TAKAKI, M. Efeitos da luz e da temperatura na germinação de sementes de Tabebuia serratifolia (Vahl) Nich, Tabebuia chrysotricha (Mart. ex DC.) Standl. e Tabebuia roseo-alba (Ridl) Sand-Bignoniaceae. Ciência Florestal, Santa Maria, RS, v. 15, n. 1, p. 87-92, 2005.

SPJUT, W. R. A systematic treatment of fruit types. In: MEMOIRS OF BOTANICAL GARDEN. New York: The New York Botanical Garden, 1994. 182 p. v. 70.

TAIZ, L; ZEIGER, E. Fisiologia vegetal. Porto Alegre: Artmed, 2004. 719 p.

VOGEL, E. F. Seedlings of dicotyledons: structure, development, types: descriptions of 150 woody Malesian taxa. Wageningen: Centre for Publishing and Documentation, 1980. $471 \mathrm{p}$.

WILLAN, R. L. Guia para la manipulacíon de semillas forestales con especial referencia a los trópicos. Roma: FAO, 1991. 502 p. 
